\title{
Correction to: Feasibility Study of a Novel Protease-Activated Fluorescent Imaging System for Real-Time, Intraoperative Detection of Residual Breast Cancer in Breast Conserving Surgery
}

Barbara L. Smith, MD, PhD ${ }^{1}$, Conor R. Lanahan, BS ${ }^{1}$, Michelle C. Specht, MD ${ }^{1}$, Bridget N. Kelly, BA ${ }^{\mathbf{1}}$, Carson Brown, BA, MS ${ }^{1}$, David B. Strasfeld, $\mathrm{PhD}^{3}$, Jorge M. Ferrer, $\mathrm{PhD}^{3}$, Upahvan Rai, $\mathbf{B S}^{\mathbf{1}}$, Rong Tang, $\mathrm{MD}^{1}$, Travis Rice-Stitt, $\mathrm{MD}^{2}$, Anna Biernacka, $\mathrm{MD}^{2}$, Elena F. Brachtel, $\mathrm{MD}^{2}$, and Michele A. Gadd, MD ${ }^{1}$

${ }^{1}$ Division of Surgical Oncology, Massachusetts General Hospital, Boston, MA; ${ }^{2}$ Department of Pathology, Massachusetts General Hospital, Boston, MA; ${ }^{3}$ Lumicell, Inc, Newton, MA

CORRECTION TO: ANN SURG ONCOL

HTTPS://DOI.ORG/10.1245/S10434-019-08158-1

The article Feasibility Study of a Novel Protease-Activated Fluorescent Imaging System for Real-Time, Intraoperative Detection of Residual Breast Cancer in Breast Conserving Surgery, written by Barbara L. Smith et al., was originally published electronically on the publisher's internet portal on January 2, 2020, without open access. With the author(s)' decision to opt for Open
Choice, the copyright of the article changed March 2020 to (C) The Author(s) 2020 and the article is forthwith distributed under a Creative Commons Attribution 4.0 International License https://creativecommons.org/licenses /by/4.0/), which permits use, sharing, adaptation, distribution, and reproduction in any medium or format, as long as you give appropriate credit to the original author(s) and the source, provides a link to the Creative Commons license, and indicates if changes were made.

The original article can be found online at https://doi.org/10.1245/ s10434-019-08158-1.

(C) The Author(s) 2020

B. L. Smith, MD, PhD

e-mail: blsmith1@mgh.harvard.edu 